Article

\title{
A Novel Geographical Information Systems Framework to Characterize Photovoltaic Deployment in the UK: Initial Evidence
}

\author{
Paul Westacott * and Chiara Candelise \\ Received: 23 October 2015; Accepted: 23 December 2015; Published: 5 January 2016 \\ Academic Editor: Andrés G. Muñoz \\ Imperial College Centre for Energy Policy and Technology (ICEPT), Imperial College London, \\ London SW7 1NA, UK; c.candelise05@imperial.ac.uk \\ * Correspondence: paul.westacott09@imperial.ac.uk; Tel.: +44-207-594-6781; Fax: +44-207-594-9334
}

\begin{abstract}
Globally, deployment of grid-connected photovoltaics (PV) has increased dramatically in recent years. The UK has seen rapid uptake reaching over 500,000 installations totalling $2.8 \mathrm{GWp}$ by 2013. PV can be installed in different market segments (domestic rooftop, non-domestic rooftop and ground-mounted "solar-farms") covering a broad range of system sizes in a high number of locations. It is important to gain detailed understanding of what grid-connected PV deployment looks like (e.g., how it deployed across different geographic areas and market segments), and identify the major drivers behind it. This paper answers these questions by developing a novel geographical information systems (GIS)-framework - the United Kingdom Photovoltaics Database (UKPVD) - to analyze temporal and spatial PV deployment trends at high resolution across all market segments. Results show how PV deployment changed over time with the evolution of governmental PV policy support. Then spatial trends as function of local irradiation, rurality (as a proxy of building and population density) and building footprint (as a proxy for roof-area) are analyzed. We find in all market segments, PV deployment is strongly correlated with the level of policy support. Furthermore, all markets show a preference to deploy in rural areas and those with higher irradiation. Finally, local clustering of PV in all market segments was observed, revealing that PV is not spread evenly across areas. This work reveals the complex nature of PV deployment, both spatially and by market segment, reinforcing the need capture this through mapping.
\end{abstract}

Keywords: photovoltaics (PV); distributed generation; geographical information systems (GIS); renewable energy policy

\section{Introduction}

Over the past few years there has been a dramatic increase in the deployment of grid-connected photovoltaics (PV) in countries across the globe. The uptake of PV at a national level initially triggered by the introduction of market-pull policies [1] has helped global reductions in PV system prices which, in turn, fostered further deployment worldwide [2]. In the United Kingdom in particular, installed capacity, grew from $32 \mathrm{MWp}$ at the end of 2009 to over $2800 \mathrm{MWp}$ (comprising around 500,000 installations) by the end of 2013 [3]. However, unlike conventional "centralized" electricity generation, PV systems are typically characterized by: smaller installation size (with generator capacity ranging from a few $\mathrm{kWp}$ to tens of MWp); numerous installation locations and the ability to be installed in the different market segments of: domestic rooftop, non-domestic rooftop and ground-mounted systems. The former two typically being connected "behind the meter" on electricity consumer's premises, whilst the latter are generally connected directly to the distribution network at higher voltage levels [4]. These features in conjunction with their variable electrical output can present new challenges 
and opportunities for the electricity networks and market [5]. For example, embedded generators have the potential to cause local voltage constraints (challenge) or reduce losses within the network (opportunity) [6]. These impacts will be strongly related to the amount of electricity exported into the network by sites with PV installed [7], which in turn depends upon the on-site PV generation and electricity consumption. Therefore it is expected to vary significantly across geographic locations and market segments. For example in the domestic market, greater value is expected from self-consumption of generated electricity (i.e., minimizing electricity import), whereas, in the ground-mount market the aim is to maximize electricity export.

In order to assess the potential impacts of PV deployment on the electricity network it is very important to firstly gain a detailed understanding of what grid-connected PV deployment looks like- both spatially and by market segment. For example, where PV has been installed, which PV system size, or by whom (i.e., is it domestic, non-domestic or ground mounted)? This paper aims at providing answers to these questions by developing a novel framework to analyze PV deployment trends in the UK.

A number of reports within the literature have considered UK PV deployment and examined how certain drivers have influenced it. For example, Cherrington et al. [8] and Muhammad-Sukki et al. [9] investigated the level of subsidy provided through a government market-pull policy and how it impacted on uptake of PV in the domestic sector. These reports demonstrated the clear influence of government policy in driving UK deployment in the domestic market. Along similar lines, the Department for Energy and Climate Change (DECC) published analysis comparing domestic PV deployment to a number of socio-economic indicators, including level of income deprivation and rurality [10]. Rurality is a measure of how dispersed domestic properties are, ranging from isolated dwellings to dense urban areas with populations over 10,000. These analyses provided a solid basis to consider the nationally aggregated trends in the domestic PV market, but did not explore in detail the influences of market segmentation or spatial variation, e.g., are these trends the same in the ground-mounted market as the domestic market? Do they differ in different geographical areas of the UK?

More recently, work by Gooding et al. [11] began to consider the importance of spatial disaggregation of the UK PV deployment. Their approach estimated the feasible PV potential of different UK cities, based upon solar resource (e.g., irradiation and appropriate roof-area) and socio-economic factors, such as income, where higher income was considered as a variable that would increase a household's ability to install PV. The research highlighted how spatial disaggregation enabled a clearer understanding of the interplay between different variables that is lost at higher levels of aggregation. In an international context, an approach adopted by Kwan [12], provided a much finer level of spatial disaggregation to study the uptake of domestic PV deployment in the US, within a geographical information system (GIS)-framework. This work probed the links between spatial deployment of PV and a range of social, economic and political variables (including level of education; household income and local governmental membership to national sustainability organizations). It demonstrated a methodology capable of distinguishing deployment at a local-level and provided new insights into the interaction between different variables shaping deployment.

In the UK context, an approach adopted by Richter [13] analyzed domestic PV deployment at post-code level to understand if social learning effects (e.g., the observation of local PV installations) influenced the deployment rate of further installations in that area. While this analysis was disaggregated spatially (i.e., it considered trends in individual post-code areas) the authors noted the limitations of assessing such areas in isolation (e.g., by not considering how deployment in one area related to that in an adjacent one), and discussed the value of future work to investigate deployment across adjacent areas. More recently, Ozkan et al. [14] investigated how trends in the UK domestic market relates to a number of variables (including the population density, proportion of detached houses and irradiation), spatially disaggregating the UK to 134 areas. This research highlighted the importance of both local features of the built-environment (e.g., percentage of detached housing) and 
wider geographical characteristics (such as aggregate population density) influencing the amount of PV deployed. The authors also discussed that further refinement of the analysis would be possible by investigating trends at a finer level of spatial disaggregation.

Clearly, a number of the studies described above have begun to consider how PV deployment varies in a spatially disaggregated manner as well as some of the underlying drivers influencing this. However, they often employ relatively coarse grained analysis, or have considered each spatial area in isolation (e.g., they don't investigate relationships of deployment in adjacent areas). Crucially, of the studies identified the focus has been almost entirely upon the domestic sector, therefore missing out a significant portion of the total installed PV, e.g., the ground-mount and non-domestic rooftop market segments. It is anticipated that PV deployment in these market segments-similar to the domestic market—will also be significantly influenced by a range of variables. For example, it would seem likely that ground-mounted PV would be more prevalent in areas of low population density (such as rural ones), or that non-domestic PV may be installed to a greater extent in areas with larger coverage of non-domestic buildings. Moreover, despite existing literature provides convincing evidence on the positive correlation between solar irradiance and PV deployment in the domestic sector [14] such evidence still has to be given for non-domestic and ground mounted market segments.

Thus it is the intention of this research to provide a framework to consider PV deployment trends disaggregated to a fine level of spatial detail and enabling comparison across all market segments. Firstly, it develops a novel GIS-based framework, the United Kingdom photovoltaics database (UKPVD), which draws together PV deployment data for over half a million installations within the UK including all market segments. PV deployment in the UK is then mapped to high spatial resolution across all market segments, with specific geographical case studies presented to capture variations within the local area. We next compare the influence of the national PV support policy, irradiation, and characteristics of the built environment on PV deployment across all market segments. These variables have been selected as they are expected to have an impact on PV deployment and are available at the required level of spatial disaggregation. Moreover, it is interesting to analyze how they have influenced deployment across market segments. These variables are intended to provide comparison between market segments opposed to an exhaustive list of all variables that shape deployment. A qualitative discussion on the role of some additional factors, which are not available at such spatial disaggregation (such as property tenure) is next presented.

This paper presents the initial outputs of the techno-economic work package of the PV2025 project, an Engineering and Physical Science Research Council (EPSRC) consortium focused on understanding the potential costs and benefits of PV for UK infrastructure and society. The framework developed here has been structured as a basis from which further work will be developed, specifically to understand: future PV deployment scenarios; potential impacts on the electricity networks; and possible mitigation measures.

The reminder of this paper is arranged as follows. Section 2 outlines the methodology developed covering both the development of the GIS-framework and analytical approach used to examine trends in deployment. Section 3 provides an overview of UK policy supporting the deployment of PV, as a key driver for uptake. Section 4 discusses trends in PV deployment and how it has been affected by UK PV policy and other variables both quantitative and qualitative. Section 5 concludes and outlines the direction of future work.

\section{Overview of Developed Geographical Information Systems Framework and Analytical Approach}

The UKPVD framework developed here is a GIS based tool to map the deployment of PV across the UK. A GIS is a computer-based tool to enable the visualization and analysis of data that contains spatial information. In the context of the PV2025 project it is valuable to identify deployment trends, consider the amount of electricity fed into the grid, implications for the electricity network and possible mitigation measures. 
The UKPVD framework is arranged into three layers (shown in Figure 1): inputs (top), databases (middle) and outputs (bottom). The inputs are the data-sources brought together within this framework. The first of these is the GIS basemaps, which provide a "blank canvas" dividing the UK into smaller spatial areas. The other inputs into the framework include PV deployment and statistical datasets that can be matched to the GIS basemaps (these are: average annual irradiation, rurality and building footprint). These inputs are then joined together to create two new databases, the PV systems database and the lower-layer super output area (LSOA) level database (Figure 1, middle). The information and relationships within these can be viewed and exported as GIS maps and statistical formats, which comprise the outputs from the framework (Figure 1, bottom). These outputs can then be analyzed in order to understand the trends in deployment. The following sections explain in more detail the data-sources and rationale for building the framework.

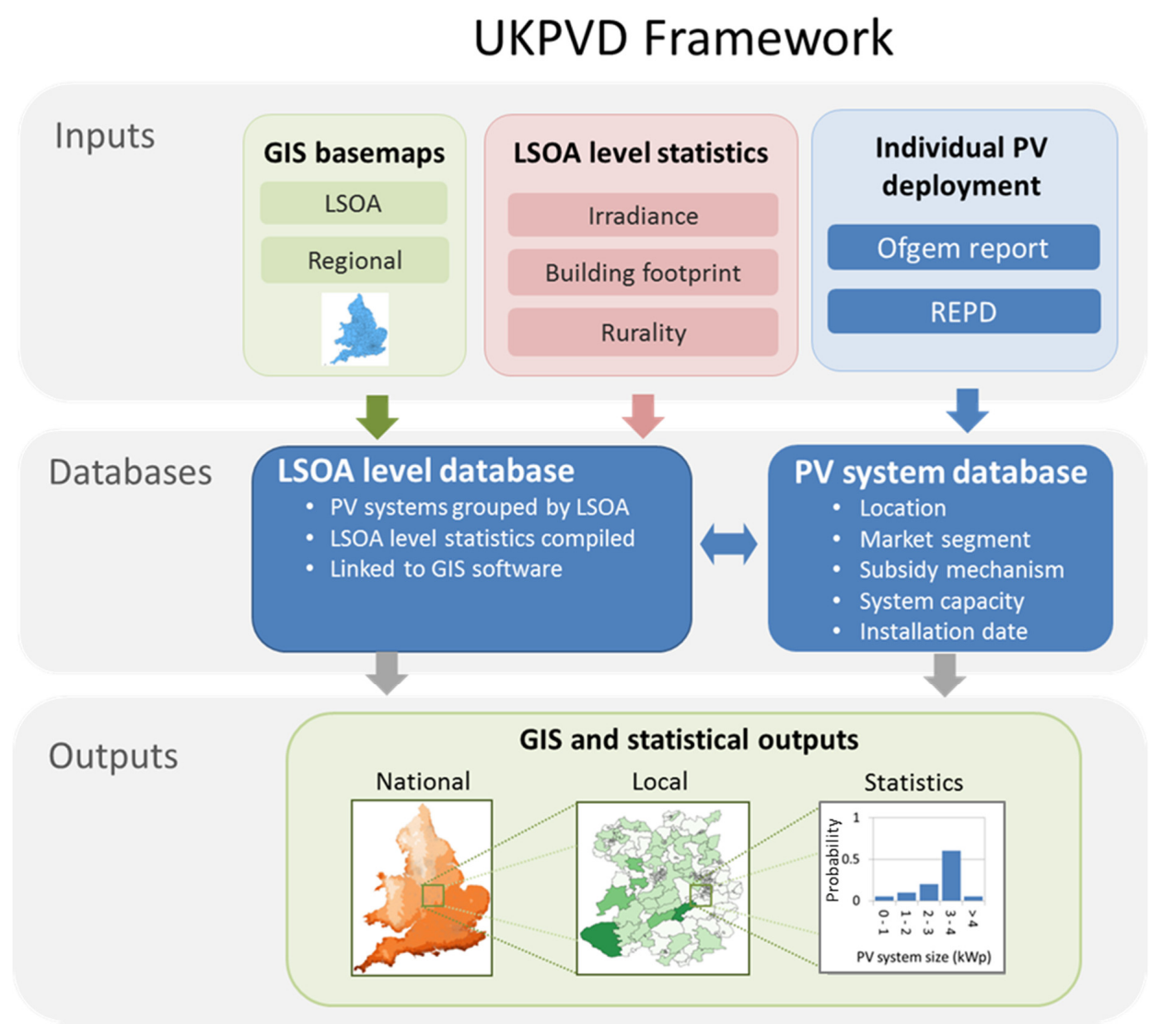

Figure 1. Schematic of the United Kingdom photovoltaics deployment (UKPVD) framework.

\subsection{Geographical Information Systems Basemaps: The Mapping Framework for Photovoltaics Deployment}

When designing the framework, the first input selected was the GIS basemap of highest spatial disaggregation, or in other words that which offers the greatest spatial resolution. In this study we use the LSOA basemap. An LSOA is a spatial unit of analysis containing on average 600 households that form spatially adjacent, socio-economically similar clusters [15]. As population characteristics (e.g., number of households) are maintained, the size $\left(\mathrm{km}^{2}\right)$ and shape of LSOAs can vary widely. The GIS input boundary map of all LSOAs in England and Wales (approximately 34,000) was obtained from the Office of National Statistics (ONS) Geoportal [16] and utilized 2001 census geography. We selected to use the LSOA for two reasons: firstly, it is the most detailed spatial disaggregation available for PV deployment data. Secondly, the LSOA is a standard area for many census-based and other geographical datasets, thus making available a broad range of compatible national datasets. 
The analysis carried out here utilised Quantum-GIS (QGIS), an open source desktop GIS package. This software was used to link the GIS basemaps to the databases created. Color maps were created in the software package to visualize spatial distribution of LSOAs and amount of PV installed, with higher deployment areas appearing darker. Statistical summaries of this data were exported for analysis in appropriate analytical software, such as Microsoft Excel.

\subsection{Lower-Layer Super Output Area Level Statistics: Variables Influencing Photovoltaics Deployment}

We selected to examine three sets of LSOA level statistics: average annual irradiation, building footprint area and rurality. These variables were selected as they have an impact on all PV deployment and enable comparisons between market segments, for example, how does the difference in irradiance across the UK influence domestic deployment relative to ground-mount? Annual irradiation is expected to have strong impact on PV deployment as it varies significantly across the UK and it affects the annual return on investment from a PV system (as higher annual irradiation will generally result in higher electricity generation, providing a higher return). Rurality is investigated to provide insights into how PV is distributed across the country, i.e., if more installed in dense urban or sparsely populated rural areas. Finally, building footprint is investigated (as proxy for roof-area) as to date no evidence has been provided comparing domestic and non-domestic buildings.

Average annual irradiation, was obtained from the PVGIS database ground-station average annual irradiation (1981-1990) on a horizontal surface [17], and a mean value per LSOA was derived (in $\mathrm{kWh} / \mathrm{m}^{2}$ ). Across England and Wales irradiation is highest in the South-West of England and gradually decreases moving further North-East, shown in Figure 2, meaning LSOAs that are close to each other spatially tend to have similar irradiation.

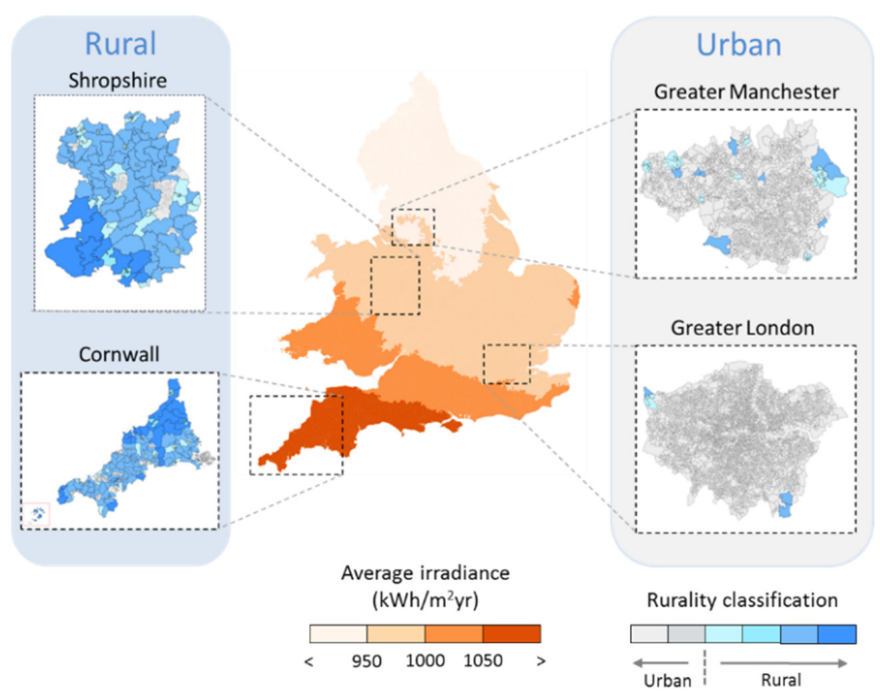

Figure 2. Selection of case study areas for domestic and non-domestic photovoltaics (PV).

Building footprint data was utilized (i.e., $\mathrm{m}^{2}$ coverage of domestic and non-domestic buildings per LSOA), as we are not currently aware of a national dataset for roof-area dis-aggregated to LSOA level, distinguishing domestic and non-domestic buildings. The building footprint area is expected to have a significant role in determining how much PV may be deployed, i.e., larger building coverage will correlate with a larger rooftop area over which to deploy PV. The dataset was acquired from the generalized land-use database of the ONS [18], we use the most recent dataset, which at time of writing was measured in 2005. Clearly changes in land-use over time (such as urbanization) will influence the validity of this data-set, and as such we have designed the framework to be updateable when new data becomes available. 
Building footprint is also a quantity that may vary significantly between LSOAs, depending on the types of building present and their size. Therefore to enable comparison of PV deployment in areas with different building footprint, we propose a utilization factor. This is calculated by dividing the installed capacity of PV $(\mathrm{kWp})$ by the building footprint $\left(\mathrm{m}^{2}\right)$, hence providing a value of PV capacity "normalized" by building area $\left(\mathrm{Wp} / \mathrm{m}^{2}\right)$. The term is useful to compare areas dissimilar in terms of building coverage (e.g., rural and urban) and also to compare trends between the different market segments (e.g., domestic and non-domestic). Rurality, which is defined here using the ONS standard classification [19], categorizes LSOAs depending on the type of settlements within them. These settlements cover: urban (population over 10,000); town and fringe; village, hamlet and isolated dwellings. In this report the latter two of these classifications are considered as rural to aid simplicity.

\subsection{Individual Photovoltaics Deployment: Photovoltaics System Data-Sources}

The final inputs into the framework are PV deployment data, gathered from two data-sources of PV installation: the Ofgem feed-in tariff (FiT) installation report [20] and the renewable energy planning database (REPD) [21]. The Ofgem report contains records of all PV systems within the UK benefiting from the FiT scheme, which was introduced in April 2010. The FiT scheme has been an important driver for PV deployment within the UK. PV systems installed prior to the FiT are likely to be encompassed into this database, as they probably applied for FiT following the schemes introduction in April 2010, in order to qualify for the significant financial benefits accruing from it. The REPD records all PV projects over $50 \mathrm{kWp}$ regardless of subsidy mechanism. Due to the potential of double-counting PV installations appearing within both the Ofgem report and REPD reports (i.e., systems between $50 \mathrm{kWp}$ and $5000 \mathrm{kWp}$ receiving FiT), duplicate records in REPD were removed. All remaining records in the REPD were assumed to be subsidized through the only other available PV policy support, the renewables obligation (RO). We believe this assumption to be reasonable as grid parity in the UK has not yet been achieved; meaning that installing a PV system without a subsidy provides a very low return on investment. In line with this assertion, a discussion of UK subsidies for PV is presented in Section 3. The analysis presented in this paper covers trends in PV deployment up to the end of 2013.

\subsection{Databases}

All of the data collected as inputs is then consolidated into two databases, the PV system database and the LSOA level database (shown in Figure 1). The PV system database contains information on each PV system that has been installed, characterized by: location, market segment, subsidy mechanism, system capacity (e.g., $\mathrm{kWp}$ ) and installation date. The PV systems database contains records of over 500,000 PV installations.

The LSOA level database provides a summary of the characteristics of each LSOA, including the total domestic and non-domestic building footprint areas $\left(\mathrm{m}^{2}\right)$, the average annual irradiance, rurality classification and also a summary of the PV installed. The latter is derived from the PV systems database, and provides the total number and installed capacity $(\mathrm{kWp})$ of PV for each market segment.

It is worthwhile to note that a number of the characteristics investigated at LSOA level, such as the amount of PV and building footprint coverage could change over time (as more PV is installed and new buildings are constructed). As such one important characteristics of this framework is the ability to update it. We update the PV system database quarterly as new information is released by Ofgem, this updated data is then used to refresh the LSOA level characteristics. Similarly as new land-use data becomes available (which currently only occurs every decade) we are able to include this into the database.

\subsection{Outputs and Analytical Approach}

The UKPVD enables investigation of both temporal and spatial trends in PV deployment. Irradiation, rurality and building-footprint are considered to be spatial variables (i.e., they vary 
geographically), whereas policy—which has changed dynamically year-on-year (see Section 3)—is considered as a temporal variable.

The temporal evolution of PV deployment is investigated on an annual basis for each market segment. This is then examined in conjunction with the introduction and evolution of the market pull policies outlined in Section 3.

To investigate the spatial variation in deployment we use case study areas instead, as this enables more localized trends to be identified. In the case of the domestic and non-domestic PV markets we select four case studies to examine how PV deployment varied between rural/urban and high/low irradiation areas. The case studies are displayed in Figure 2, two urban and two rural areas, for different levels of irradiation (the colour scheme on the central map denotes average annual irradiation and the colour scheme of left and right panels distinguishes urban and rural LSOA classification) We selected two highly urban case study regions, Greater London and Greater Manchester, as these are two of the largest metropolitan areas within England and Wales and collectively account for just under $17 \%$ of its total population [22]. Greater London is significantly further south than Greater Manchester and as a result has higher annual irradiation (as demonstrated in Figure 2) thus allowing us to compare PV deployment in similar urban areas but with different levels of irradiation. The selected rural regions are Cornwall and Shropshire. Cornwall was chosen as it has the highest irradiation in the UK (as shown in Figure 2) and hence any effects of irradiation on PV deployment are expected to be most pronounced here. Shropshire was selected because of its lower irradiation, but similar distribution of LSOA rurality to Cornwall (shown by the similar range of colours in Figure 2, left), thus providing a spatial distribution of population comparable to Cornwall. The rural case studies incorporated the full counties of Cornwall and Shropshire with all urban LSOAs filtered out. In the case of ground-mounted PV we compare the deployment at a regional rather than LSOA level as the number of ground-mounted installations is significantly lower than the rooftop markets (see Section 4). Thus the larger geographical areas provide a higher number of data per region, enabling a clearer comparison. For completeness and comparison of PV deployment across all market segments, domestic and non-domestic deployment is also mapped at a regional level. ONS definition of regions are used [16]. PV system sizes $(\mathrm{kWp})$ in the non-domestic and ground mount markets may vary significantly, due to the large possible variation in non-domestic building size and available land-area for ground mount PV. As a consequence of this we also characterize the sizes of PV systems in these markets within the spatially disaggregated analysis.

\section{Policy Support for Photovoltaics in the UK}

To date, policy support has been the main driver for PV deployment in the UK and, despite the dramatic reduction of PV prices in the recent years, PV grid parity has not yet been achieved and policy incentives are still needed for further PV uptake [1,23]. Hence, understanding UK PV deployment requires an understanding of the main PV policy support mechanisms introduced and their evolution over time (we here focus on the national policies implemented, as analysis of local government policy is outside the scope of this initial study). Their impact on PV deployment is then discussed in the Section 4.

Initial policy support to PV deployment was introduced in 2000 through the domestic and large-scale field trails, then followed by the major demonstration programme (2002-2006) and the low carbon building programme (2006) [24,25]. In 2002 a policy to support a number of renewable technologies (including onshore wind and PV), known as the RO was introduced. The RO was introduced as a technology neutral support mechanism, meaning that generators of all eligible low-carbon technologies were able to claim one RO certificate (ROC) per MWh of generated electricity. Electricity suppliers were required to obtain a certain amount of ROCs relative to their total annual electricity supply, thereby creating demand for the certificates. However, the RO had relatively little uptake from less established technologies (e.g., PV) due in part to the complexity of the mechanism, which was ill-suited to less established, higher-risk technologies and industries comprised 
of smaller players [26]. Following this relatively low uptake, the RO was re-banded in 2009, with less established technologies, including PV, receiving two ROCs per MWh, which was fixed until April 2013, an overview of the evolution of the RO is provided in Table 1.

Table 1. Renewables obligation (RO) policy evolution, number of ROC/MWh available for PV and ROC buy-out price ( $£ / R O C)$. RO certificate: ROC.

\begin{tabular}{ccccccc}
\hline Band & $\begin{array}{c}\text { April 2002 } \\
\text { RO } \\
\text { Introduced }\end{array}$ & $\begin{array}{c}\text { April 2009 } \\
\text { Technology } \\
\text { Specific }\end{array}$ & $\begin{array}{c}\text { April 2013 } \\
\text { Split by Market } \\
\text { Segment }\end{array}$ & April 2014 & $\begin{array}{c}\text { April 2015 } \\
<5 \text { MWp }\end{array}$ & April 2016 \\
\hline Ground-mount (Stand-alone) & 1 & 2 & 1.6 & 1.4 & 1.3 & 1.2 \\
Rooftop & 1 & 2 & 1.7 & 1.6 & 1.5 & 1.4 \\
Buy-out Price (£/ROC) & - & $£ 37.19$ & $£ 42.02$ & $£ 43.30$ & - & - \\
\hline
\end{tabular}

However, despite the re-banding of the RO, it was not until the introduction of the FiT scheme in April 2010 that PV deployment experienced significant growth. The FiT was designed to promote the deployment of PV systems below $5 \mathrm{MWp}$ in capacity, it worked by paying electricity generators a premium tariff for each $\mathrm{kWh}$ of electricity they produced. The tariff paid is banded and dependent upon the capacity $(\mathrm{kWp})$ of the generator, with the largest systems receiving the lowest tariff rate. The banding within the FiT is shown in Table 2, along with the authors interpretation of how tariff bands relate to the market segments considered herein. The smallest band, $0-4 \mathrm{kWp}$, is expected to be the focus of the domestic market [8]. The non-domestic rooftop market can encompass the entire range, e.g., $0-5000 \mathrm{kWp}$ of system capacity (evidence of the actual break-down is in presented in Section 4). Ground-mount PV systems are also eligible for the FiT, and are distinguished through a separate stand-alone banding.

Table 2. Feed-in tariff banding and revisions for PV. Feed-in tariff: FiT.

\begin{tabular}{|c|c|c|c|c|c|}
\hline $\begin{array}{l}\text { Tariff Band } \\
\qquad(\mathbf{k W p})\end{array}$ & $\begin{array}{l}\text { Proposed } \\
\text { Market } \\
\text { Segment }\end{array}$ & $\begin{array}{l}\text { April } 2010 \mathrm{FiT} \\
\text { Introduced } \\
\text { Tariff }(\mathrm{p} / \mathrm{kWh})\end{array}$ & $\begin{array}{c}\text { August } 2011 \\
\text { Fast-Track Review } \\
\text { (\% change) }\end{array}$ & $\begin{array}{c}\text { February } 2012 \\
\text { Comprehensive Review } \\
\text { Phase } 1 \text { ( } \% \text { change) }\end{array}$ & $\begin{array}{c}\text { August } 2012 \\
\text { Comprehensive Review } \\
\text { Phase } 2 \mathrm{~A} \text { ( } \% \text { change) }\end{array}$ \\
\hline $0-4$ & Domestic & 48.07 & $\mathrm{~N} / \mathrm{A}$ & $-54 \%$ & $-24 \%$ \\
\hline $4-10$ & $\begin{array}{c}\text { Domestic/ } \\
\text { non-domestic }\end{array}$ & 41.93 & $\mathrm{~N} / \mathrm{A}$ & $-58 \%$ & $-14 \%$ \\
\hline $10-50$ & Non-domestic & 36.53 & $\mathrm{~N} / \mathrm{A}$ & $-56 \%$ & $-11 \%$ \\
\hline 50-100 & Non-domestic & 36.53 & $-42 \%$ & $-35 \%$ & $-11 \%$ \\
\hline $100-150$ & Non-domestic & 34.10 & $-38 \%$ & $-35 \%$ & $-11 \%$ \\
\hline $150-250$ & Non-domestic & 34.10 & $-51 \%$ & $-18 \%$ & $-15 \%$ \\
\hline 250-05000 & Non-domestic & 34.10 & $-72 \%$ & $\mathrm{~N} / \mathrm{A}$ & $-20 \%$ \\
\hline Stand-alone & Ground-mount & 34.10 & $-72 \%$ & $\mathrm{~N} / \mathrm{A}$ & $-20 \%$ \\
\hline
\end{tabular}

a The authors' interpretation of how banding relates to market segments. This does not reflect a policy intent from the Department for Energy and Climate Change (DECC).

Further to the generation tariff, PV system owners were also paid for the electricity they exported back to the grid [8]. Both components of the pricing were contracted for 25 years, with payments being made by the electricity supplier, who passed these costs onto their customers. Following the introduction of the FiT, the PV deployment across the UK was significantly higher than had initially been anticipated [27], meaning the annual cost of supporting PV deployment was also higher than expected, presenting a challenge for government in the context of budgetary control. The high deployment was in part due to declining module prices, reducing the capital cost of PV systems [2]. In February 2011 a review of the FiT was announced. This terminally comprised four separate stages, three of which were relevant to PV: the Fast-Track Review [27] and Comprehensive Review Phase 1 [28] and Comprehensive Review Phase 2A [29].

The Fast-Track Review, implemented in August 2011, reduced considerably the level of FiT tariffs for systems above $50 \mathrm{kWp}$. This reduction was between $38 \%$ and $72 \%$, with the biggest reductions for 
larger capacity bands. Table 2 displays in the initial rates of FiT and the percentage reduction, based on previous rate. The reduction was rationalised by DECC as "ensuring that the scheme continues to support the range of small- scale installations for which it was designed" [27] and was implemented six months after the initial review announcement.

In February 2012 Comprehensive Review Phase 1 came into effect, reducing the FiT tariffs for all PV systems below $250 \mathrm{kWp}$ in capacity, with reductions of up to $58 \%$ for systems under $4 \mathrm{kWp}$ (i.e., predominantly domestic PV). In addition, the review linked FiT rate to the buildings energy efficiency, whereby only more efficient buildings could claim the highest FiT rate.

Comprehensive Review Phase 2A, implemented 1 August 2012, reduced the length of the FiT from 25 years to 20 years, and importantly, introduced a triggered degression mechanism. In this mechanism, market activity, not policy intervention provided the degression of the tariff. For example, if quarterly deployment in a certain band (e.g., 0-4 kWp) surpasses a deployment threshold, then a percentage decrease in FiT rate for the subsequent period will occur, thereby providing a degree of self-regulation, which is more visible to the market.

Amidst FiT reviews, in 2013 the RO was also reformed [30] with the banding for PV was split into distinct categories for ground-mount and rooftop PV, with the rooftop systems receiving a higher ROC rate. This decision was based on the acknowledgement by DECC that building mounted systems requires higher levels of support when compared to ground-mounted ones. Additionally, as of April 2015, recent amendments to ROC eligibility criteria mean that only PV systems below 5 MWp will be eligible for the RO [31]. After this amendment large PV systems ( $>5 \mathrm{MWp}$ ), will be eligible to bid into the new contract for difference (CfD) mechanism, where they will compete in a technology neutral auction process to acquire contracts for electricity generation at a fixed "strike" price.

This changing landscape currently leaves PV with various potential subsidy mechanisms, depending on the system size and market segment. For example, all systems below $50 \mathrm{kWp}$ in size are eligible for FiT. Whereas systems between $50 \mathrm{kWp}$ and $5 \mathrm{MWp}$ are eligible for FiT or RO; in the case of FiT the level of support depends on the system capacity (with larger systems receiving lower FiT rates), whereas the RO depends on the market segment, with building mounted system receiving more ROCs. The impact of the introduction and revision of the FiT and RO upon PV deployment in the different market segments is discussed in the following section. In the analysis presented below (i.e., pre 2014) it is worthwhile to note that systems above $5 \mathrm{MWp}$ were still eligible for the RO.

\section{Results and Discussion}

Results from the UKPVD framework on PV deployment trends over time and spatially across England and Wales are here presented. Furthermore, the influence of policy, irradiation, building footprint and rurality on these trends are examined.

\subsection{Photovoltaics Deployment over Time: The Role of Policy}

Annual and cumulative installed capacity over time and by market segment is displayed in Figure 3. Following the introduction of the FiT scheme in April 2010 significant growth in deployment across all market segments has been observed, with the annual installation growing from $30 \mathrm{MWp}$ in 2010 to around $1 \mathrm{GWp}$ in 2011. This growth has been mainly due to the domestic market segment and ground-mount and to a lesser extent to non-domestic installations. The end of 2011 and beginning of 2012 saw the implementation of the Fast-track (August 2011) and Comprehensive Phase 1 (February 2012) reviews, which affected the level of FiT for all system sizes (and hence market segments). These policy changes coincided with the significant decrease in annual installation across all market segments in 2012. Moreover, 2013 saw a continued decline in annual installation across the domestic and non-domestic market segments, in line with the further reductions to the FiT across all tariff bands through Comprehensive Review Phase 2A (August 2013). However the ground-mount market saw a dramatic rise of installed capacity in 2013, despite this reduction in FiT. 
To investigate why the annual installed capacity of ground-mount market did not follow the trend observed in the other segments, we consider: how system sizes have changed over time, the level of support available through different subsidy mechanisms, and the utilization of these mechanisms (Figure 4).

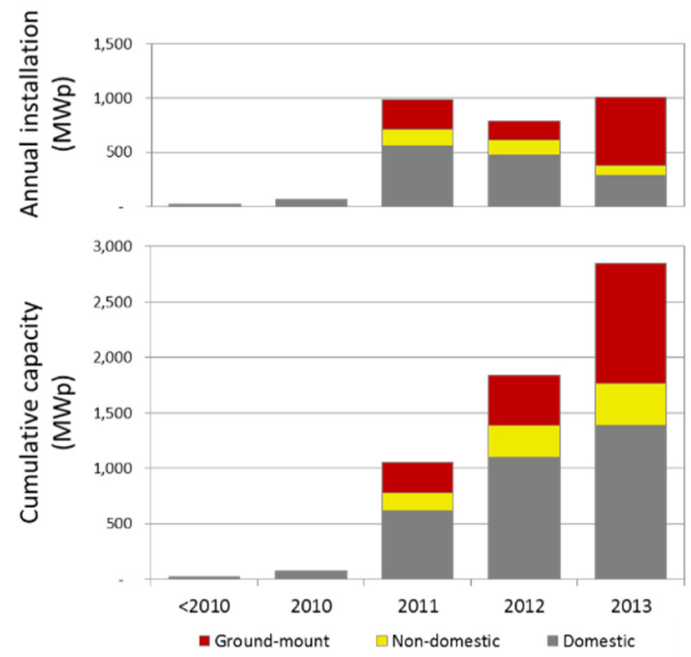

Figure 3. Annual and cumulative deployment of PV in England and Wales.

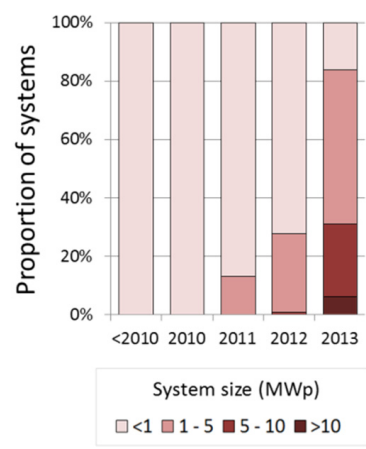

(a)

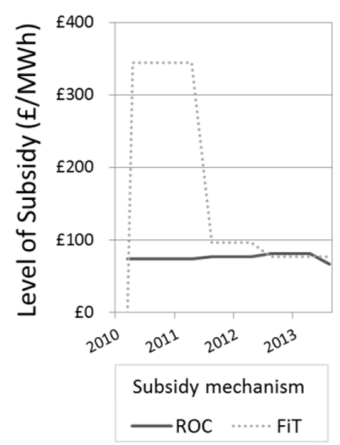

(b)

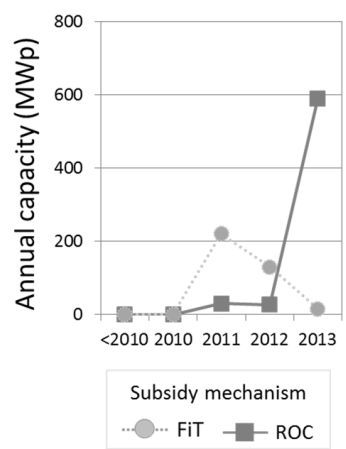

(c)

Figure 4. Annual ground-mount PV deployment by (a) system size; (b) level of subsidy and (c) deployment by subsidy type.

Firstly we observe a progressive increase in size of PV ground mounted plants since 2010. This can be rationalized as larger projects are expected to benefit from greater economies of scale in capital cost, increasing the return on investment of a project [32]. Moreover, since 2010 a combination of global PV module prices dramatically reducing and domestic learning-by-doing across the whole UK PV value chain due to a steadily expanding UK PV market has led strong investment cost reductions at PV system level as well as reduced project risks thus enabling larger projects to be built.

Between 2010 and 2013 the level of support for ground-mount PV under the FiT decreased significantly. On the other hand, the RO support (displayed per MWh of generation) remained relatively constant in the region of 75-80 £ / MWh (calculated by multiplying the annual buy-out price per ROC by the number of ROCs per MWh). By 2013 however there was little difference between the average subsidy between the two mechanisms. It is worthwhile to note however there is a significant difference between the certainty of future revenue via two mechanisms. The RO is a tradable certificate (with a variable and uncertain future price) whereas the FiT provides a fixed premium (certain future price) [33]. Thus while the FiT provided lower risk revenue it also capped systems at $5 \mathrm{MWp}$. Hence for larger systems to utilize the $\mathrm{RO}$ it may be expected that the revenue risk of this mechanism must be 
outweighed by the improved economies of scale in capital cost inherent in building larger ( $>5 \mathrm{MWp})$ plants. The utilization of the two subsidy mechanisms (Figure 4c) reveals that this tipping-point appears to have occurred during 2013, when a large increase in RO utilization occurred. This transfer between subsidy mechanisms is also reflected in the system sizing (Figure 4a), where close to a third of all installed systems in 2013 were above 5 MWp.

\subsection{Spatial Trends in Photovoltaics Deployment}

To examine spatial trends in PV deployment we firstly look at regional installed capacity at the end of 2013 across England and Wales disaggregated by market segment (Figure 5). The size of the pie-charts represents total regional capacity and average annual irradiation is displayed in the background, number of installations per region is presented in Table 3. Deployment in all market segments is significantly higher in higher irradiation (southern) regions, when compared to the lower irradiation (northern) ones, both in number of installations and capacity (MWp). This effect is most pronounced in the ground-mount market, where around half installations (177 of 353) are within the single highest irradiation region (South-West), and only around $5 \%$ are collectively installed across the three most northern regions. These differences lead to variations in the market segmentation at a regional level. For example, in the South West and South East ground-mounted PV is the largest contributor to capacity, whilst there is minimal ground mount capacity in the northern regions (Yorkshire and Humber, North East and North West), where capacity is dominated by domestic PV.

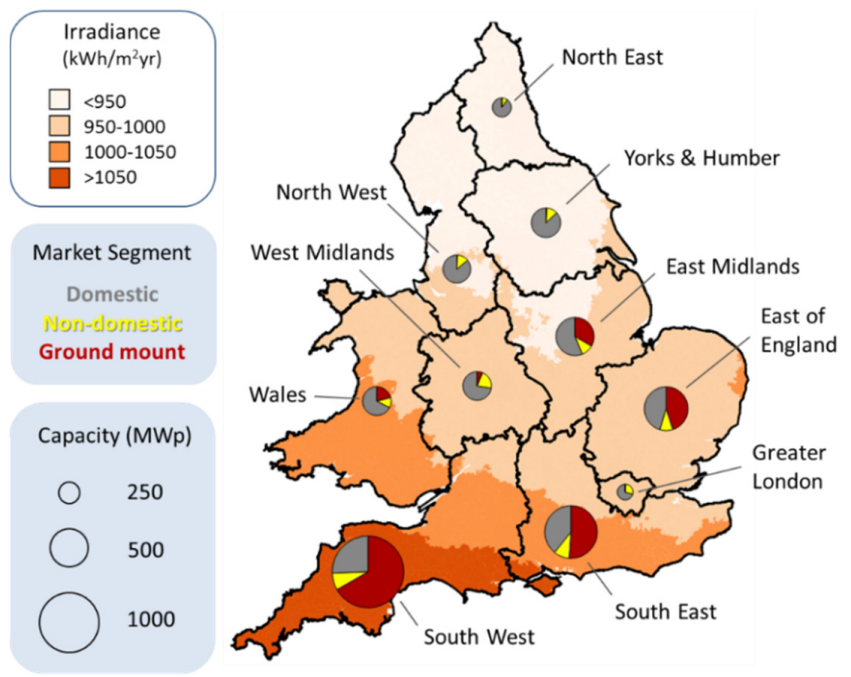

Figure 5. Regional total installed PV capacity by market segment (in 2013).

Table 3. Number of regional PV installations and average annual irradiance.

\begin{tabular}{ccccc}
\hline \multirow{2}{*}{ Region } & $\begin{array}{c}\text { Average irradiance } \\
\left(\mathbf{k W h} / \mathbf{m}^{\mathbf{2}} \mathbf{y r}\right)\end{array}$ & \multicolumn{3}{c}{ Number of installations } \\
\cline { 3 - 5 } & & Domestic & Non-domestic & Ground-mount \\
\hline North East & 916 & 21,240 & 704 & 1 \\
North West & 934 & 41,870 & 928 & 4 \\
Yorks \& Humber & 936 & 44,220 & 1075 & 12 \\
East Midlands & 939 & 46,260 & 1075 & 27 \\
West Midlands & 970 & 35,330 & 1871 & 9 \\
East of England & 982 & 50,140 & 1367 & 2 \\
Greater London & 986 & 11,950 & 681 & 17 \\
Wales & 1003 & 32,880 & 903 & 172 \\
South East & 1006 & 63,310 & 1503 & 177 \\
South West & 1052 & 73,010 & 2154 & $\mathbf{3 5 3}$ \\
Total & - & $\mathbf{4 2 0 , 2 0 0}$ & $\mathbf{1 2 , 2 6 1}$ &
\end{tabular}




\subsubsection{Domestic Photovoltaics}

Domestic PV was the largest market segment by 2013, both by capacity (1400 MWp, Figure 5) and number of installations (420,000, Table 3). Table 4, provides a comparison of the four case study areas. The geographic characteristics (rurality, average annual irradiation and number of LSOAs) are presented in conjunction with aggregate domestic PV deployment trends. The urban case studies, Greater London and Greater Manchester, contain a far greater number of LSOAs (e.g., thousands as opposed to hundreds) due to their significantly higher populations (as an LSOA contains on average 600 households). Similarly, urban areas also have a much greater domestic building footprint (i.e., larger total coverage of buildings in $\mathrm{m}^{2}$ ), when compared to the rural ones of Shropshire and Cornwall.

Table 4. Key features of domestic and non-domestic PV deployment in the case studies.

\begin{tabular}{|c|c|c|c|c|}
\hline Classification & Cornwall & Shropshire & Greater London & Greater Manchester \\
\hline Rurality & Rural & Rural & Urban & Urban \\
\hline Number of LSOAs & 199 & 124 & 4765 & 1646 \\
\hline Average irradiance $\left(\mathrm{kWh} / \mathrm{m}^{2} \mathrm{yr}\right)$ & 1084 & 968 & 985 & 946 \\
\hline Aggregate domestic values & - & - & - & - \\
\hline Total installed PV capacity (MWp) & 28 & 12 & 34 & 40 \\
\hline Total building footprint $\left(\mathrm{km}^{2}\right)$ & 16 & 11 & 138 & 63 \\
\hline Utilisation factor $\left(\mathrm{Wp} / \mathrm{m}^{2}\right)$ & 1.7 & 1.1 & 0.24 & 0.63 \\
\hline Total number of systems & 7731 & 2834 & 12,317 & 14,227 \\
\hline LSOA level domestic statistics & - & - & - & - \\
\hline Minimum PV per LSOA $(\mathrm{kWp})$ & 0 & 0 & 0 & 0 \\
\hline Median PV per LSOA (kWp) & 71 & 43 & 3.7 & 14 \\
\hline Maximum PV per LSOA (kWp) & 454 & 346 & 256 & 357 \\
\hline Max/median value & 6.3 & 8.0 & 70 & 25 \\
\hline Mean PV per LSOA & 140 & 96 & 7.1 & 24 \\
\hline Aggregate non-domestic values ${ }^{a}$ & - & - & - & - \\
\hline Total installed PV (MWp) & 10 & 6.8 & 14 & 6.0 \\
\hline Total building footprint $\left(\mathrm{km}^{2}\right)$ & 9.4 & 9.6 & 75 & 37 \\
\hline Utilisation factor $\left(\mathrm{Wp} / \mathrm{m}^{2}\right)$ & 1.0 & 0.70 & 0.19 & 0.16 \\
\hline Total number of systems & 362 & 239 & 706 & 190 \\
\hline Number of systems below $50 \mathrm{kWp}$ & 348 & 226 & 681 & 176 \\
\hline Number of systems above $50 \mathrm{kWp}$ & 14 & 13 & 25 & 14 \\
\hline
\end{tabular}

All four case studies show a total installed PV capacity in the order of 10s MWp, with Greater Manchester exhibiting the highest (40 MWp) and Shropshire the lowest (12 MWp), indicating substantial deployment of domestic PV in all areas. However, the utilization factor (calculated by dividing the total installed capacity by total domestic footprint), is significantly lower in urban areas compared to rural ones $\left(0.24 \mathrm{Wp} / \mathrm{m}^{2}\right.$ and $0.63 \mathrm{Wp} / \mathrm{m}^{2}$ for London and Manchester and $1.7 \mathrm{Wp} / \mathrm{m}^{2}$ and $1.1 \mathrm{Wp} / \mathrm{m}^{2}$ for Cornwall and Shropshire respectively) revealing a significantly lower amount of PV installed per square meter of building coverage in urban areas. It is also worthwhile to note the higher utilization of building footprint for Cornwall, when compared to Shropshire, which correlates with the tendency to deploy PV in higher irradiation areas (as discussed above). However the picture of urban case studies is less clear in this respect, as Greater London has a lower utilization factor and indeed lower total installed capacity than Greater Manchester despite having higher irradiation. Additional factors leading to this atypical result, as well as the differences between rural/urban areas are discussed in Section 4.3.

To examine in more detail how building footprint relates to installed PV capacity, we disaggregated the case study data to LSOA level (presented as scatter plots in Figure 6). In all cases a positive trend is observed whereby increasing building footprint correlates with a higher installed PV capacity. 
Rural areas show steeper gradients than urban ones $(\mathrm{m}$, inset) confirming the greater tendency to install PV for a given building footprint. The strength of the correlation (observed through the data scatter and R-squared values) is far lower in both urban cases, indicating a very weak relationship with building footprint in the urban cases. The lower utilization and weaker correlation may be explained by the dominance of other factors—-such as property tenure-influencing deployment within these urban areas, as further discussed in Section 4.3.

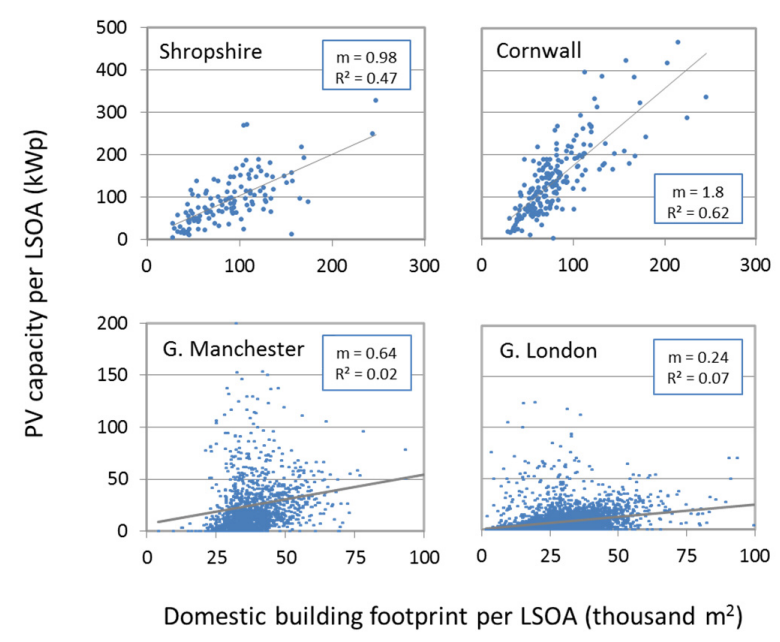

Figure 6. Domestic PV capacity against building footprint per lower-layer super output area (LSOA).

Insets show gradient (m) and R-squared values.

The spatial characteristics of installed domestic PV capacity per LSOA in rural and urban case studies are presented in Figures 7 and 8 respectively. The maps of rural case studies show a large range of installed PV per LSOA, which is heterogeneously distributed across the area. Some LSOAs have a relatively high concentration of PV (thus appearing darker on the map), whereas others located close-by have relatively little installed. As also seen above, the installed capacity per LSOA is generally much lower in urban than rural areas, with a significant number of urban LSOAs exhibiting no PV installed (those appearing white in Figure 8). A summary of PV capacity per LSOA (minimum, median and maximum) within each case study is detailed in Table 4. All case studies contain at least one LSOA with PV deployment above $250 \mathrm{kWp}$ (which is considered to be relatively high as this relates to around 80 domestic PV systems in an area of around 600 households). This level of deployment is many times greater than the median and mean capacities in each case study area, demonstrating the local clustering of PV deployment. This finding also demonstrates the framework's ability to identify the presence and location of high deployment areas, something which would be lost at higher levels of aggregation.
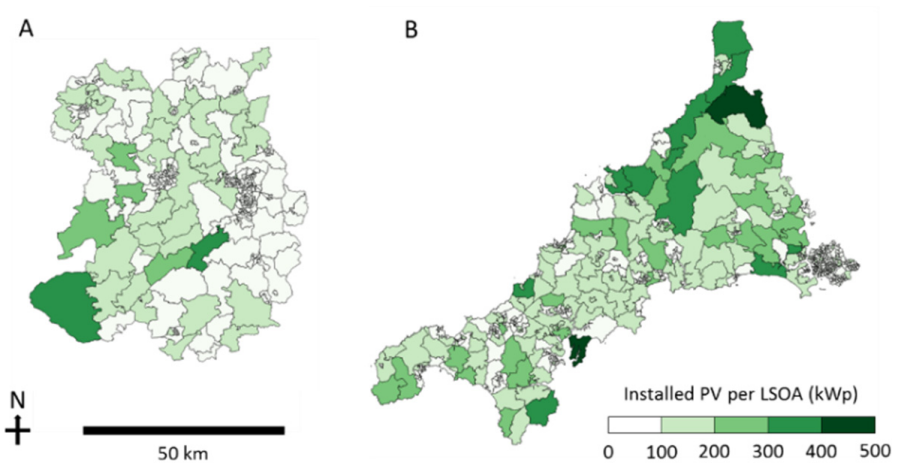

Figure 7. Domestic PV deployment in rural case study regions of (A) Shropshire and (B) Cornwall. 

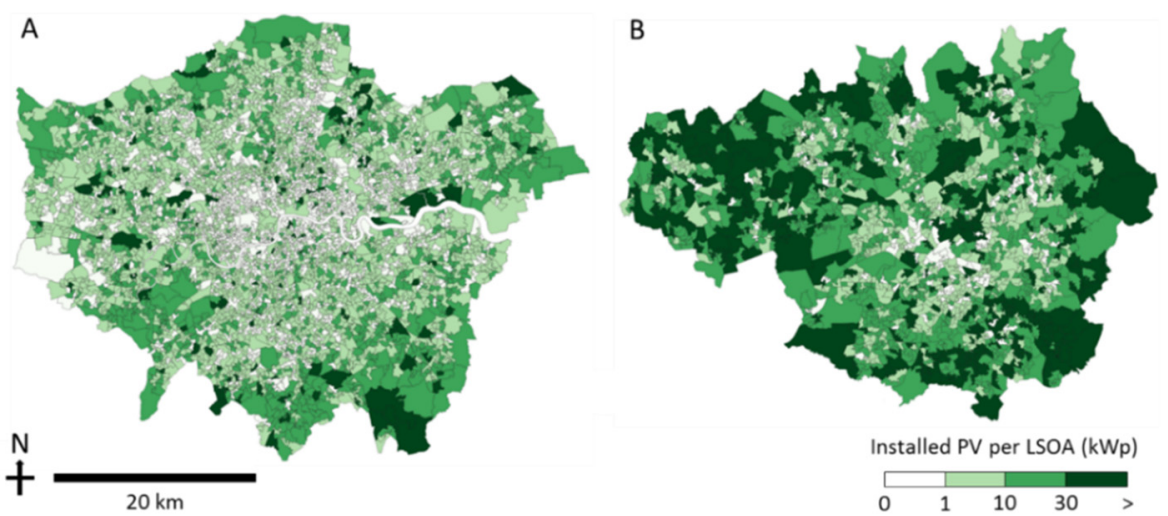

Figure 8. Domestic PV deployment in urban case studies, (A) Greater Manchester and (B) Greater London.

\subsubsection{Non-Domestic Photovoltaics}

The non-domestic rooftop market is so far the smallest segment within the UK. By 2013 there were only $350 \mathrm{MWp}$ of capacity spread over 12,000 installations, ranging from around $2 \mathrm{kWp}$ to around $5 \mathrm{MWp}$. The total installed non-domestic capacity in each case study is shown in Table 4 and ranges between $6 \mathrm{MWp}$ and $14 \mathrm{MWp}$ (Manchester and London, respectively). In all areas the total non-domestic PV capacity and utilization factors are lower than their domestic counterparts, indicating a lower tendency to install PV within the non-domestic market in all areas investigated.

Comparison between the rural and urban areas reveals that-similar to the domestic market-the utilization of non-domestic building footprint is higher in rural areas than urban ones. In both the rural and urban cases the non-domestic utilization factors are greater in higher irradiation areas (Cornwall and Greater London) when compared to their lower irradiation counterparts (Shropshire and Greater London). This is in agreement with the results presented in Table 3, which show a greater tendency to deploy more non-domestic PV in higher irradiation areas.

The wide variation in non-domestic system sizes are characterized in Figure 9 where, the national aggregate distribution of system sizes and capacity for England and Wales (denoted $E \mathcal{E} W$ ) is presented. PV systems below $50 \mathrm{kWp}$ account for $95 \%$ of all installations, and approximately $55 \%$ of the total capacity. The breakdown for each case study shows a similar trend, with installations below $50 \mathrm{kWp}$ consistently accounting for over $90 \%$ of the installations and over half of the installed capacity; to put this into context the whole of Greater Manchester has only 14 systems above $50 \mathrm{kWp}$ (Table 4). These system sizing trends are common across rural/urban and low/high irradiation areas and as such may be shaped by national factors (e.g., policy) as opposed to more local variables of irradiation and rurality. A discussion of the factors influencing the low deployment of systems above $50 \mathrm{kWp}$ is presented in Section 4.3.

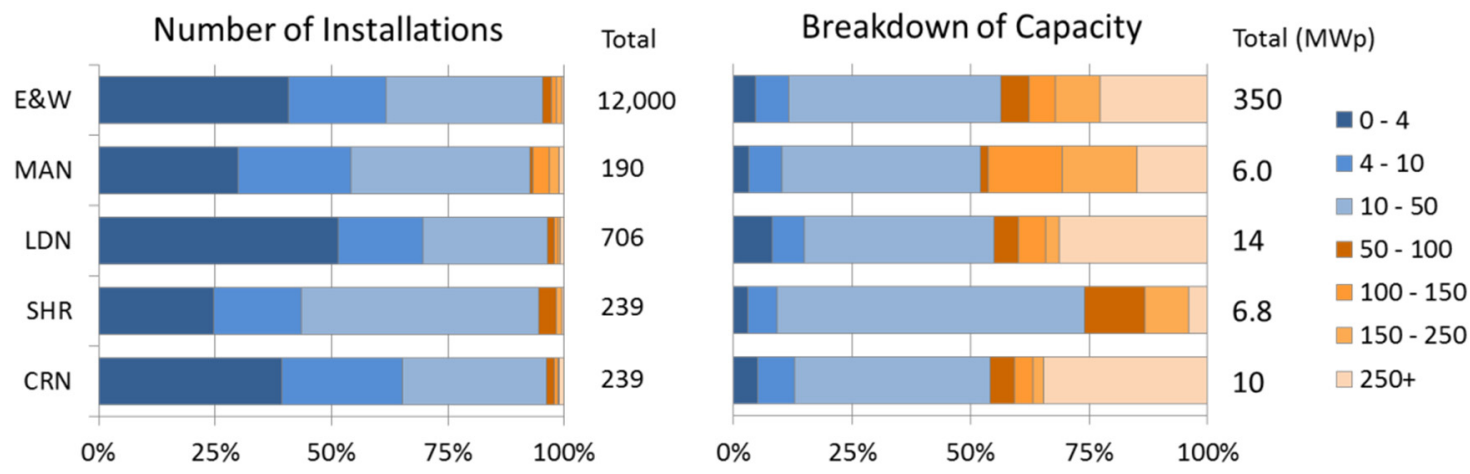

Figure 9. Breakdown of non-domestic PV installations by number and capacity (MWp). 
The spatial distribution of non-domestic PV installations within the case studies is mapped in Figures 10 and 11. As the number of non-domestic installations is relatively low and the variation in system size high, deployment is mapped by number of installations, opposed to capacity. The urban case studies reveal that most LSOAs have no non-domestic PV systems installed; revealing that in these LSOAs domestic PV will likely be the dominant sector. The rural case studies on the other hand have a much larger portion of LSOAs containing at least one non-domestic system, indicating a greater number of non-domestic installations for a given number of households (i.e., per LSOA).
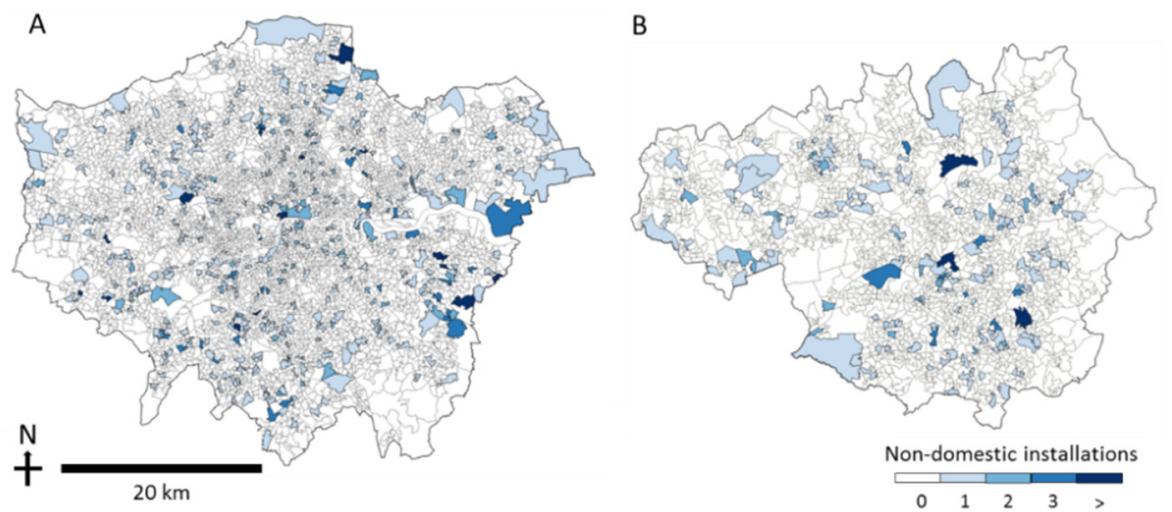

Figure 10. Non-domestic PV deployment in urban case studies, (A) Greater Manchester and (B) Greater London.

A

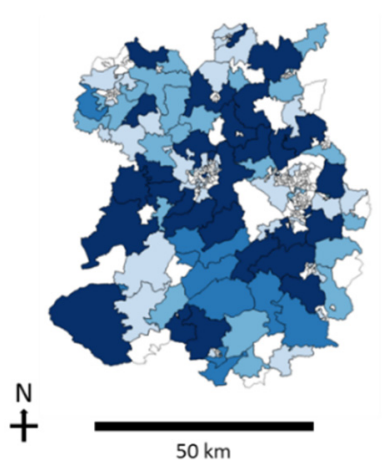

B

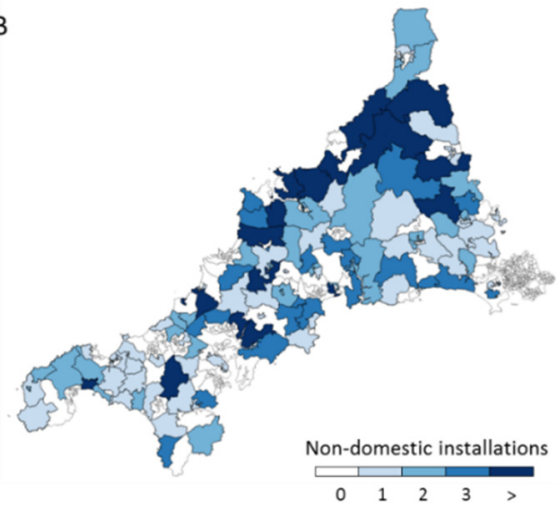

Figure 11. Non-domestic PV deployment in rural case studies, (A) Shropshire and (B) Cornwall.

\subsubsection{Ground-Mount}

Within the UK, the ground-mounted PV sector comprises the lowest number of installations with 353 systems by 2013. However the larger size of these systems result in a cumulative capacity contribution over $1 \mathrm{GWp}$ (Figure 3). As discussed at the beginning of Section 4, the cumulative regional capacity of ground-mount PV appears to be strongly influenced by irradiation. To understand the underlying features of this trend, we disaggregate regional installations by system size (Figure 12), with regions ordered by irradiation (numerical irradiation values given in Table 3). This figure highlights that not only are more systems installed in higher irradiation areas, but the size of individual systems tends to increase with irradiation. For example, the low irradiation northern regions all ground mount systems are below $1 \mathrm{MWp}$, whereas the higher irradiation areas systems above $1 \mathrm{MWp}$ are the most common.

From Figure 12, it is also clear that there are certain areas where deployment deviates from the overall irradiation trend observed. For example, the West-Midlands and the East of England have similar irradiation, but the deployment is substantially higher in the latter. A map of the location 
of individual systems is displayed in Figure 13. This map demonstrates that the local deployment of individual systems is not homogenous, with some areas exhibiting significant local clustering of systems (notably in the South-West of England), whilst other relatively large areas have no systems installed. These differences in regional capacity and the more local inhomogeneity may indicate the presence of more localized factors (such as local planning applications or grid-connection offers) shaping deployment, further discussed in Section 4.3.

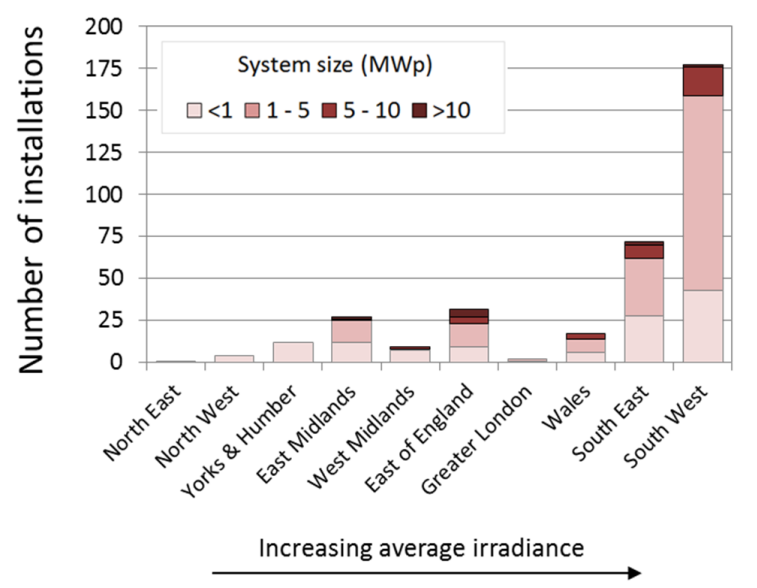

Figure 12. Regional installations of ground-mount PV by system size band (MWp).

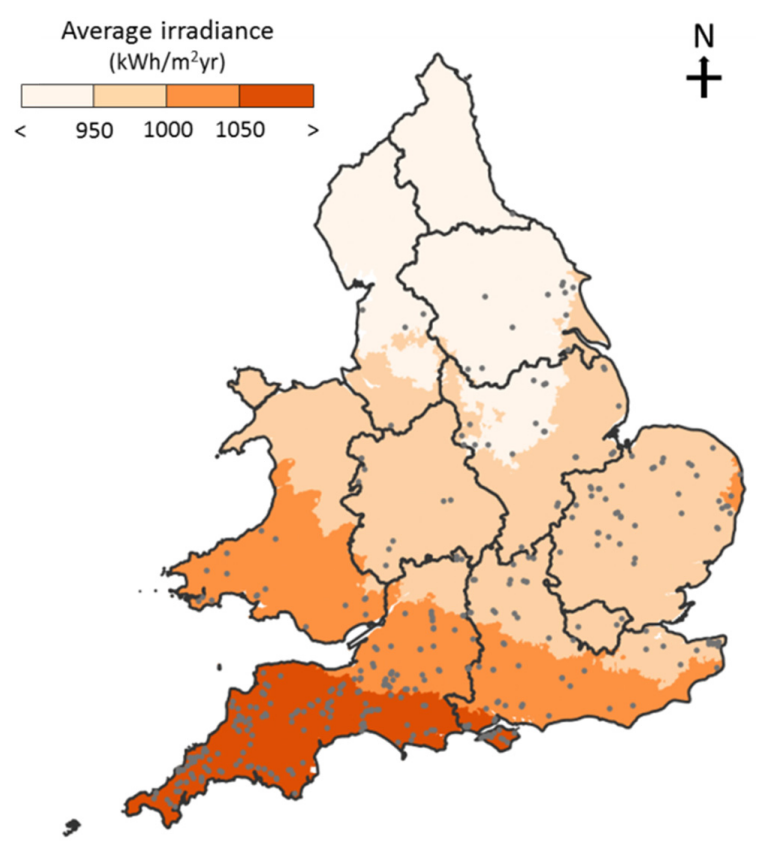

Figure 13. Distribution of individual ground-mount PV installations (shown as grey dots) across England and Wales.

\subsection{Additional Factors that May Influence Photovoltaics Deployment}

As demonstrated above, the role of a number of drivers influencing deployment has been clearly observed (such as variation with irradiation). However it also appears that a number of other potentially competing factors played an important role. The following section sets out some consideration of what these factors may be in order to help inform the direction of future research.

In the case of domestic and non-domestic PV a lower utilization of building footprint in urban areas was observed, when compared to rural ones. Between these areas there may be a number 
of differences in the: building stock (i.e., building and roofing type); proportion of property tenure (owner occupied, private rented, housing association, etc.); and building stock turn-over rate. Each of these may have an effect on the probability of installing PV. For example in the domestic market, the likelihood of installing a PV system may be higher in an owner occupied property, where the investor would benefit from the value of the FiT and reduced electricity import directly, and over a long period of time. Indeed, the English housing survey [34]—which presents national statistics relating to the characteristics of the UK housing stock - reveals substantial differences between urban and rural areas, with urban areas exhibiting a significantly lower portion of owner-occupiers and higher portions of private renters. Furthermore it also shows differences in the types of building and roofing materials utilized, with urban areas having a larger portion of flat (asphalt and felt) roofing, and high-rise apartment blocks (i.e., tall buildings encompassing a large number of households, but with little roof area), although to the authors knowledge these datasets are not available at the level of spatial disaggregation presented in the above analysis. Both of these may negatively impact the ability to install PV for a given building footprint. For example, it is likely that well oriented area available for a PV system is lower on a flat roof than a pitched roof for a given footprint; moreover the property tenure arrangements in blocks of flats are likely more complex, due to the larger number of parties involved, which may provide an additional barrier to deployment. These factors may provide some explanation of the differences observed between PV deployment in urban and rural areas, and may also provide an insight into the atypical results observed when comparing Greater Manchester and Greater London, where the former had substantially lower deployment in the domestic market, despite having higher irradiation and greater building footprint.

The non-domestic market has had the lowest uptake within the UK, notably above $50 \mathrm{kWp}$. Section 3 outlined some of the policy developments, which led to the largest reduction in FiT above $50 \mathrm{kWp}$, through the Fast-Track and Phase 1 reviews [27,28], likely reducing the return on investment (and subsequently deployment) in this market. In addition to this, systems above $50 \mathrm{kWp}$ face a number of non-subsidy barriers that may have limited deployment. These include more complex planning, grid-connection and subsidy application processes. These factors may add to the risk, timescale and cost of such projects. At the time of writing the government are consulting on a proposal to extend permitted development (i.e., developments that do not require planning permission) to PV systems of $1 \mathrm{MWp}$ [35] for building-mounted systems, which may help to stimulate deployment by removing this barrier. Further research into the impact of these barriers would be valuable to more clearly identify their relative contribution.

In the ground-mount market an overall irradiation dependence was observed. However at a local level, the distribution of individual systems appeared to be inhomogeneous. This likely indicates the role of other factors shaping deployment. Indeed, there are a number of location specific variables which could contribute to this, including: land-availability, local community engagement and proximity to an appropriate grid-connection point. For example, if there is strong local opposition to PV deployment it is likely that a lower portion of presented ground-mount applications will be successful. In addition, if grid-connection to the local distribution network is expensive (due to e.g., the need of local network reinforcement), it will likely provide a location specific financial signal to deter deployment in that area. Similarly, if deployment has been high in an area (e.g., the South-West), then the networks hosting capacity will be reduced [36] and hence future deployment in that area may be limited as the area becomes "saturated". Unless sufficient hosting capacity becomes available (which currently occurs through network reinforcement), then it is likely that over time new deployment moves to other regions, where sufficient hosting capacity is present.

\section{Conclusions}

In conclusion, we have developed and demonstrated a novel GIS-based framework to map and analyze trends in PV deployment across all locations and market segments within the UK. The high spatio-temporal resolution of this analysis has provided a novel tool to analyze this evolving 
deployment from bottom up and in detail, presenting — to our knowledge—the first comparison of PV deployment across all UK market segments.

The analysis highlights a number of key findings about deployment. Firstly, that the non-domestic rooftop market is significantly under-developed compared to the domestic and ground-mount markets. Additionally, the investigation showed that PV deployment across the UK is highly diverse. At a local level, small areas of high PV deployment were identified. At a regional level the composition of installed PV by market segment varied significantly. These differences are important as they reveal how the benefits from solar photovoltaics are spread across different areas and markets, for example how households and businesses benefit. Furthermore, the findings reinforce the importance of disaggregating PV deployment to sensitive spatial resolution and by market segment in order to build a realistic picture of what this deployment actually looks like.

The relationship of PV deployment with policy, irradiation, rurality and building footprint were examined revealing a number of common trends across market segments. Firstly, the role of market-pull policies has been instrumental in stimulating deployment in all markets. Interestingly markets have responded differently to these policies. The non-domestic market has consistently had the lowest deployment, whereas the ground-mount market grew quickly and transitioned from utilizing the FiT to the $\mathrm{RO}$ as larger projects became more viable. Similarly all market segments demonstrated a positive relationship with irradiation, with the strongest effect in the ground-mount market, and weakest effect in the domestic market. Deployment in all markets was higher in rural areas, which hosted virtually all ground-mount PV and had higher utilization of building footprint for domestic and non-domestic PV.

While the framework has provided a valuable step to characterise PV deployment, it is worthwhile to note its limitations and how these could be overcome in future works. Firstly, the spatial framework used (e.g., LSOAs) aggregates PV deployment across groups of around 600 households and cannot capture more localised trends (such as how PV is spread between two adjacent streets). Being able to picture and analyse these differences may be useful to examine more clearly the factors shaping deployment. Additionally, the analysis considered building coverage as a constant over time. While this is a pragmatic assumption for the analysis presented here (due to data availability), the framework could be enhanced by characterising how such variables change over time, e.g., to capture urbanization trends or changes in building use. If an online database of such information was available the framework could be automatically updated with this information.

We also acknowledge that this study focused on a subset of variables on PV deployment, and as such does not provide a comprehensive picture of all factors that have driven PV deployment to date. Future analysis could investigate how PV deployment is influenced by the proportion of owner-occupied households across the UK, or differences in local planning policy. The framework and case studies developed here would provide a useful platform for such analysis. Indeed, if a wider range of variables can be identified and measured they could be added to the framework to provide deeper understanding of PV deployment drivers and future trends (e.g., by performing econometric analysis on the large dataset developed).

The framework could also be used to understand the impacts of PV deployment. For example, it could be used to map PV deployment against the level of fuel poverty in order to assess whether and under which conditions distributed generation could help in improving access to energy across the UK. This work would provide evidence on impacts of current policy support to PV deployment as well as valuable insight to shape future policies on both distributed generation and fuel poverty reduction. Similarly, the framework will be used to assess the impacts of PV deployment on local electricity networks by overlaying maps of PV generation with those of electricity demand. In addition the framework could be extended to account for broader ranges of technologies. For example, one area of emerging PV innovation is building integrated PV (BIPV), where PV generating materials can be incorporated into building facades, etc. [37]. The framework could hence be adapted to investigate building facade area as well as roof space to consider how much PV could be installed in 
the future [38]. More broadly the methodology would be useful to consider other energy technologies, such as combined heat and power (CHP) which can also be applied at domestic and non-domestic building scale and at a district-level. This combined approach would be valuable to consider the real impacts of low-carbon technology deployment and how it may be managed in the future.

Acknowledgments: We are very grateful to the UK's Engineering and Physical Sciences Research Council (EPSRC) for financial support via EP/K02227X/1. PW also acknowledges the Imperial Colleges EPSRC Impact Acceleration Account (EP/K503733/1), which provided the opportunity to disseminate the outcomes of this work through a knowledge transfer secondment.

Author Contributions: Both authors contributed equally to this work.

Conflicts of Interest: The authors declare no conflict of interest.

\section{References}

1. Sarasa-Maestro, C.J.; Dufo-López, R.; Bernal-Agustín, J.L. Photovoltaic remuneration policies in the European Union. Energy Policy 2013, 55, 317-328. [CrossRef]

2. Candelise, C.; Winskel, M.; Gross, R.J.K. The dynamics of solar PV costs and prices as a challenge for technology forecasting. Renew. Sustain. Energy Rev. 2013, 26, 96-107. [CrossRef]

3. Department of Energy and Climate Change Solar Photovoltaics Deployment-August 2014. Available online: https://www.gov.uk/government/statistics/solar-photovoltaics-deployment (accessed on 9 September 2014).

4. Pepermans, G.; Driesen, J.; Haeseldonckx, D.; Belmans, R.; D'haeseleer, W. Distributed generation: Definition, benefits and issues. Energy Policy 2005, 33, 787-798. [CrossRef]

5. Patterson, W. Transforming Electricity: The Coming Generation of Change; Routledge: London, UK, 1999.

6. Thomson, M.; Infield, D.G. Impact of widespread photovoltaics generation on distribution systems. IET Renew. Power Gener. 2007, 1, 33-40. [CrossRef]

7. Demailly, F.; Ninet, O.; Even, A. Numerical tools and models for Monte Carlo studies of the influence on embedded generation on voltage limits in LV grids. IEEE Trans. Power Deliv. 2005, 20, 2343-2350. [CrossRef]

8. Cherrington, R.; Goodship, V.; Longfield, A.; Kirwan, K. The feed-in tariff in the UK: A case study focus on domestic photovoltaic systems. Renew. Energy 2013, 50, 421-426. [CrossRef]

9. Muhammad-Sukki, F.; Ramirez-Iniguez, R.; Munir, A.B.; Mohd Yasin, S.H.; Abu-Bakar, S.H.; McMeekin, S.G.; Stewart, B.G. Revised feed-in tariff for solar photovoltaic in the United Kingdom: A cloudy future ahead? Energy Policy 2013, 52, 832-838. [CrossRef]

10. Identifying Trends in the Deployment of Domestic Solar PV under the Feed-in Tariff Scheme; Department of Energy and Climate Change: London, UK, 2012.

11. Gooding, J.; Edwards, H.; Giesekam, J.; Crook, R. Solar City Indicator: A methodology to predict city level PV installed capacity by combining physical capacity and socio-economic factors. Sol. Energy 2013, 95, 325-335. [CrossRef]

12. Kwan, C.L. Influence of local environmental, social, economic and political variables on the spatial distribution of residential solar PV arrays across the United States. Energy Policy 2012, 47, 332-344. [CrossRef]

13. Richter, L.L. Social Effects in the Diffusion of Solar Photovoltaic Technology in the UK; University of Cambridge: Cambridge, UK, 2013.

14. Balta-Ozkan, N.; Yildirim, J.; Connor, P.M. Regional distribution of photovoltaic deployment in the UK and its determinants: A spatial econometric approach. Energy Econ. 2015, 51, 417-429. [CrossRef]

15. Office of National Statistics. Super Output Areas explained. Available online: http://www.neighbourhood. statistics.gov.uk/dissemination/Info.do?m=0\&s=1409919562575\&enc=1\&page=nessgeography /

superoutputareasexplained/output-areas-explained.htm\&nsjs=true\&nsck=false\&nssvg=false\&nswid=1280 (accessed on 1 December 2014).

16. Office of National Statistics. Office of National Statistics Geoportal. Available online: https://geoportal. statistics.gov.uk/geoportal/catalog/main/home.page (accessed on 1 December 2014).

17. Šúri, M.; Huld, T.A.; Dunlop, E.D.; Ossenbrink, H.A. Potential of solar electricity generation in the European Union member states and candidate countries. Sol. Energy 2007, 81, 1295-1305. [CrossRef] 
18. Office of National Statistics. Generalised Land-use Database. Available online: http://data.gov.uk/dataset/ land_use_statistics_generalised_land_use_database (accessed on 1 December 2014).

19. Office of National Statistics. Rural/Urban Definition (England and Wales). Available online: http:/ /www.ons.gov.uk/ons/guide-method/geography/products/area-classifications/rural-urbandefinition-and-la/rural-urban-definition-england-and-wales-/index.html (accessed on 1 December 2014).

20. OFGEM Feed-in Tarif Register. Available online: https://www.ofgem.gov.uk/publications-and-updates/ feed-tariff-installation-report-30-september-2014 (accessed on 1 May 2015).

21. Department of Energy and Climate Change. Renewnable Energy Planning Database. Available online: https://www.gov.uk/government/statistics/renewable-energy-planning-database-monthly-extract (accessed on 1 June 2015).

22. Office of National Statistics. 2011 Census, Population and Household Estimates for England and Wales. Available online: http://www.ons.gov.uk/ons/rel/census/2011-census/population-and-householdestimates-for-england-and-wales—unrounded-figures-for-the-data-published-16-july-2012/index.html (accessed on 1 December 2014).

23. Lopez-Polo, A.; Haas, R.; Panzer, C.; Auer, H. Prospects for grid-parity of photovoltaics due to effective promotion schemes in major countries. In Proceedings of the 2012 Asia-Pacific Power and Energy Engineering Conference (APPEEC), Shanghai, China, 27-29 March 2012.

24. Low Carbon Building Programme 2006-2011 Final Report; Department of Energy and Climate Change: London, UK, 2011.

25. Domestic Photovoltaic Field Trails: Final Technical Report; Department of Trade and Industry: London, UK, 2006.

26. Woodman, B.; Mitchell, C. Learning from experience? The development of the Renewables Obligation in England and Wales 2002-2010. Energy Policy 2011, 39, 3914-3921. [CrossRef]

27. Feed-in Tariffs Scheme: Summary of Responses to the Fast-track Consultation and Government Response; Department of Energy and Climate Change: London, UK, 2011.

28. Feed-in Tariffs Scheme Government Response to Consultation on Comprehensive review Phase 1-Tariffs for Solar PV; Department of Energy and Climate Change: London, UK, 2012.

29. Feed-in Tariffs Scheme Government Response to Consultation on Comprehensive Review Phase 2A: Solar PV Cost Control; Department of Energy and Climate Change: London, UK, 2012.

30. Renewables Obligation Banding Review for the Period 1 April 2013 to 31 March 2017; Department of Energy and Climate Change: London, UK, 2013.

31. Government Response to Consultation on Changes to Financial Support for Solar PV Part A: Controlling Spending on Large-scale Solar PV within the Renewables Obligation Part B: Promoting the Deployment of Mid-scale Building-Mounted Solar PV in the Feed-in; Department of Energy and Climate Change: London, UK, 2014.

32. Fthenakis, V.; Mason, J.E.; Zweibel, K. The technical, geographical, and economic feasibility for solar energy to supply the energy needs of the US. Energy Policy 2009, 37, 387-399. [CrossRef]

33. Candelise, C.; Gross, R.; Leach, M.A. Conditions for photovoltaics deployment in the UK: The role of policy and technical developments. Proc. Inst. Mech. Eng. Part A J. Power Energy 2010, 224, 153-166. [CrossRef]

34. English Housing Survey; Department for Communities and Local Government: London, UK, 2008.

35. Technical Consultation on Planning; Department for Communities and Local Government: London, UK, 2014.

36. Harrison, G.P.; Piccolo, A.; Siano, P.; Wallace, A.R. Hybrid GA and OPF evaluation of network capacity for distributed generation connections. Electr. Power Syst. Res. 2008, 78, 392-398. [CrossRef]

37. Roy, J.; Betts, T.R.; Gottschalg, R. Accuracy of Energy Yield Prediction of Photovoltaic Modules. Jpn. J. Appl. Phys. 2012, 51. [CrossRef]

38. Reale, A.; Cinà, L.; Malatesta, A.; De Marco, R.; Brown, T.M.; Di Carlo, A. Estimation of Energy Production of Dye-Sensitized Solar Cell Modules for Building-Integrated Photovoltaic Applications. Energy Technol. 2014, 2, 531-541. [CrossRef]

(C) 2016 by the authors; licensee MDPI, Basel, Switzerland. This article is an open access article distributed under the terms and conditions of the Creative Commons by Attribution (CC-BY) license (http:/ / creativecommons.org/licenses/by/4.0/). 